\title{
Stage III Distal Bile Duct Cancer AJCC v7
}

National Cancer Institute

\section{Source}

National Cancer Institute. Stage III Distal Bile Duct Cancer A/CC v7. NCI Thesaurus. Code C88094.

Stage III includes: T4, Any N, M0. T4: Tumor involves the celiac axis or the superior mesenteric artery. M0: No distant metastasis. (from AJCC 7th Ed.) 